\title{
Adhesive performance of a caries infiltrant on sound and demineralised enamel
}

\author{
Wiegand, A ; Stawarczyk, B ; Kolakovic, M ; Hämmerle, C H F ; Attin, T ; Schmidlin, P R
}

\begin{abstract}
The use of a caries infiltrant before application of a conventional adhesive did not impair bonding to sound and demineralised enamel and might be beneficial as a pretreatment in demineralised enamel.
\end{abstract}

DOI: https://doi.org/10.1016/j.jdent.2010.10.010

Posted at the Zurich Open Repository and Archive, University of Zurich

ZORA URL: https://doi.org/10.5167/uzh-50245

Journal Article

Accepted Version

Originally published at:

Wiegand, A; Stawarczyk, B; Kolakovic, M; Hämmerle, C H F; Attin, T; Schmidlin, P R (2011). Adhesive performance of a caries infiltrant on sound and demineralised enamel. Journal of Dentistry, 39(2):117-121. DOI: https://doi.org/10.1016/j.jdent.2010.10.010 
Adhesive performance of a caries infiltrant on sound and demineralised enamel

Short title: Bond strength achieved by a caries infiltrant

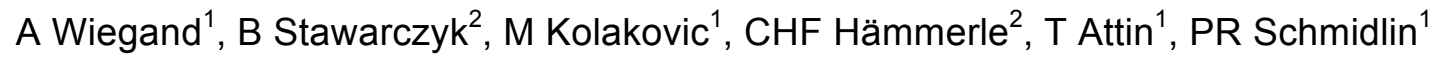

${ }^{1}$ Department for Preventive Dentistry, Periodontology and Cariology, University of Zurich, Plattenstrasse 11, 8032 Zürich, Switzerland

${ }^{2}$ Department for Fixed and Removable Prosthodontics and Dental Material Science, University of Zurich, Plattenstrasse 11, 8032 Zürich

\section{Corresponding author}

PD Dr. Patrick R. Schmidlin

Department for Preventive Dentistry, Periodontology and Cariology, University of Zurich Plattenstrasse 11, 8032 Zürich, Switzerland

Email: patrick.schmidlin@zzmk.uzh.ch

Phone: 0041-44-6343417 


\section{Abstract}

Objective: Resin infiltration is considered as a treatment option for initial caries lesions. As cavitated early lesions might require additional restorative intervention, a caries infiltrant might be also used for enamel conditioning prior to composite insertion. This study aimed to analyse the shear bond strength of a flowable composite to sound and demineralised enamel pretreated with a caries infiltrant, a conventional adhesive or a combination of both.

Methods: Flattened bovine enamel specimens $(n=120)$ were either demineralised $(14 d$, acidic buffer, $\mathrm{pH}$ 5) or remained untreated. Sound and demineralised specimens (each $n=20$ ) were then treated with: 1) $35 \%$ phosphoric acid, conventional adhesive 2) $15 \%$ hydrochloric acid, caries infiltrant or 3) $15 \%$ hydrochloric acid, caries infiltrant, conventional adhesive. Shear bond strength of a flowable composite was tested after $24 \mathrm{~h}$ water storage $\left(37^{\circ}\right)$ and statistically analysed (ANOVA, $p \leq 0.05$ ). The mode of failure was assessed microscopically at 40x magnification.

Results: On demineralised enamel, the combination of caries infiltrant and conventional adhesive showed significantly higher shear bond strength values than the conventional adhesive alone, while both being not significantly different from group 2. No significant differences between the groups could be detected on sound specimens. A higher percentage of cohesive failures could be observed in demineralised samples of group $2(40 \%)$ and 3 (65\%), while all other specimens presented almost only adhesive failures.

Conclusion: The use of a caries infiltrant before application of a conventional adhesive did not impair bonding to sound and demineralised enamel and might be beneficial as a pretreatment in demineralised enamel.

Keywords: Enamel, demineralisation, caries infiltration, adhesion, shear bond strength, failure modes 


\section{Introduction}

The infiltration of caries lesions with low viscosity light curing resins is considered as treatment option for non-cavitated lesions which are not expected to arrest or remineralize. In contrast to the conventional sealing concept where a resin layer is created on the surface, caries infiltrants aim to penetrate the porous lesion body competely. ${ }^{1}$ Compared to dental adhesives or fissure sealants, caries infiltrants were optimized for rapid capillary penetration and exhibit a very low viscosity, low contact angles to enamel and high surface tensions. ${ }^{2}$ Thus, laboratory experiments demonstrated a significantly deeper penetration in the lesion body than conventional adhesives. ${ }^{3-5}$

Due to the low viscosity of the infiltrant and as no resin coating is required, the clinical application on tooth surfaces which are difficult to access, e.g. proximal surfaces, became possible ${ }^{6,7}$ Recently, it was shown that a caries infiltrant reduced proximal lesion progression to the same extent as a fissure sealant in situ. ${ }^{8}$ As a positive side effect, white spot lesions of smooth surfaces might be masked by infiltrating the microporosities responsible for the whitish appearance of lesion. ${ }^{9}$

However, on the other hand, extensive active white spot lesions might exhibit superficial albeit cavitated defects ${ }^{10}$ which require additional restorative treatment. Likewise, proximal enamel caries lesions might be underestimated by radiographic or visual examination. Up to $30 \%$ of proximal enamel lesions considered as not cavitated were shown to already exhibit a cavitation. ${ }^{11-13}$

Thus, initial but cavitated enamel lesions might require both infiltration of demineralised parts of the lesion as well as restoration of the cavitated areas. Under clinical considerations, the treatment of these lesions could be simplified if the infiltration of the demineralised parts could be done in the same step as the bonding of enamel for composite application.

Therefore, the aim of the present study was to analyse the shear bond strength of a flowable composite to sound or demineralised enamel which was pretreated with a caries infiltrant system, a conventional adhesive or a combination of both. 


\section{Methods}

Specimen preparation

Specimens were prepared from 120 extracted bovine permanent incisors, which were stored in $0.5 \%$ chloramine solution for 7 days followed by storage in distilled water for 14 days after extraction. The teeth were cleaned and sectioned at the enamel-cementum junction using a water-cooled cutting wheel. The crowns were embedded in cylindrical moulds $(25 \mathrm{~mm}$ in diameter) filled with an auto-polymerizing acrylic resin (ScandiQuick, ScanDia, Hagen, Germany). The labial surfaces of the crowns were ground flat (SiC paper, 400 grit, Buehler, Lake Bluff, USA) under water cooling until a flat area of at least $5 \mathrm{~mm} \times 5 \mathrm{~mm}$ was exposed. Then, half of the specimens were immersed for $14 \mathrm{~d}$ in an acidic buffer containing $3 \mathrm{mM}$ $\mathrm{CaCl}_{2} \times 2 \mathrm{H}_{2} \mathrm{O}, 3 \mathrm{mM} \mathrm{KH}_{2} \mathrm{PO}_{4}, 50 \mathrm{mM}$ lactic acid, $6 \mu \mathrm{M} \mathrm{MHDP}, \mathrm{KOH}$ to adjust the initial $\mathrm{pH}$ to 5.0 and traces of thymol. ${ }^{14}$ The buffer was renewed each second day to keep the $\mathrm{pH}$ constant.

Bonding procedure and preparation for shear bond testing

Each 20 sound and 20 demineralised specimes were randomly assigned to three groups and treated as follows:

1. The enamel surface was etched for $60 \mathrm{~s}$ with $35 \%$ phosphoric acid (UltraEtch $35 \%$, Ultradent Products, South Jordan, USA), and then rinsed distilled water for $60 \mathrm{~s}$. After air drying of the surface, an unfilled adhesive (Heliobond, Ivoclar Vivadent, Schaan, Liechtenstein) was applied and gently rubbed in for $20 \mathrm{~s}$ with a microbrush, then thinned with mild air (1-2 s) and light cured for 20 s (3M ESPE Elipar S10, 3M ESPE, Seefeld, Germany).

2. The enamel surface was etched for 2 min with 15\% hydrochloric acid (Icon Etch, DMG, Hamburg, Germany) and then rinsed with water spray for $30 \mathrm{~s}$. Air drying of the surface was followed by application of ethanol (Icon Dry, DMG, Hamburg, Germany) for $30 \mathrm{~s}$ and additional air drying. Then, the low-viscosity resin infiltrant (Icon Infiltrant, DMG, Hamburg, Germany) was applied on the surface for 3 min by means of the 
sponge applicator provided with the resin infiltration system. After light-curing for $40 \mathrm{~s}$, the infiltrant was applied for further $60 \mathrm{~s}$ and again light-cured for $40 \mathrm{~s}$.

3. Enamel surfaces by hydrochloric acid etching and the resin infiltrant system as described for group 2. Then, the unfilled adhesive was applied for $20 \mathrm{~s}$ on the pretreated surface and light-cured for $20 \mathrm{~s}$ as described above.

The composition of the conventional adhesive and the caries infiltrant system based on the manufacturer's instructions are listed in Table 1.

An acrylic hollow cylinder with an inner diameter of $3 \mathrm{~mm}$ and a height of $4 \mathrm{~mm}$ was pressed on the enamel surface by means of a special bonding device described in detail previously. ${ }^{15}$ A flowable composite (Tetric EvoFlow, Ivoclar Vivadent, Schaan, Liechtenstein, LOT: N01643) was applied in two layers of each $1.5 \mathrm{~mm}$ thickness and light-cured for $60 \mathrm{~s}$ (3M ESPE Elipar S10, 3M ESPE, Seefeld, Germany).

The specimens were carefully removed from the device and stored in distilled water at $37^{\circ}$ for $24 \mathrm{~h}$.

Shear bond strength measurement

Shear bond strength was tested with a universal testing machine (Z010, Zwick, Ulm, Germany). A shear force was applied to the enamel-composite interface through a chiselshaped loading device positioned parallel to the enamel surface at a crosshead speed of 1 $\mathrm{mm} / \mathrm{min}$. Load at fracture was recorded and shear bond strength was calculated using the load at failure and the adhesive area.

For fracture mode analysis, the debonded area was examined with a stereomicroscope at 25x magnification (M3B, Wild, Heerbrugg, Switzerland). Failure mode was considered as adhesive if it occurred in the interface and as cohesive if the failure affected at least parts of the substrate (enamel or flowable composite) 


\section{Statistical analysis}

Descriptive statistics for shear bond strength (mean \pm standard deviation, $95 \%$ confidence intervals $(\mathrm{Cl})$ ) were computed and statistically analysed by One-way analysis of variance (ANOVA) followed by Bonferroni post-hoc test (Stat View 4.51, Abacus Concepts). The level of significance was set at $p \leq 0.05$.

Additionally, relative frequencies of adhesive and cohesive failures in each group were calculated at $95 \% \mathrm{Cl}$.

\section{Results}

Shear bond strength and failure modes of sound and demineralised enamel treated with the conventional adhesive, the caries infiltrant system or a combination of both are presented in Table 2.

Generally, demineralised specimens revealed significantly higher bond strength values than sound enamel $(p \leq 0.001)$. However, while shear bond strength in sound enamel was not significantly different between the different groups $(p=0.28)$, significant differences could be detected in demineralised specimens $(p=0.0081)$. Thereby, specimens treated with the caries infiltrant system followed by the adhesive exhibited significantly higher bond strength values than the adhesive alone, while both groups were not significantly different from group 2 (caries infiltrant system).

With regard to the failure mode, sound enamel presented only adhesive failures, while demineralised specimens treated with the caries infiltrant and the caries infiltrant followed by the adhesive showed a high percentage ( $40 \%$ and $65 \%$, respectively) of cohesive failures in enamel. 


\section{Discussion}

This study demonstrated that the initial shear bond strength of a caries infiltrant system on sound and demineralised enamel is comparable to the adhesive performance of a conventional adhesive.

In the present study, shear bond strength was obtained on bovine teeth, which are widely used in adhesion as well as resin infiltration tests. ${ }^{8,16}$ Shear bond strength measurements of different substrates revealed equal or, depending on the adhesives tested, only slightly different values between bovine and human enamel, ${ }^{17,18}$ so that bovine enamel is accepted as substitute for human enamel in enamel bonding tests. ${ }^{19}$

Generally, higher shear bond strength values could be observed in artificially demineralised compared to sound specimes, as demineralised enamel allows a deeper penetration of adhesives or infiltrants. Artificial enamel lesions were created following previous studies investigating resin infiltration in vitro and were shown to exhibit the typical histological structure of enamel caries (intact surface layer, body of lesion, demineralisation front). ${ }^{20-23}$ Samples were treated with the caries infiltrant system or the conventional adhesive, respectively, following manufacturers` recommendations, thus etching was performed with $15 \%$ hydrochloric acid or $35 \%$ phosphoric acid, respectively. Previous studies by Paris et al. $^{24,25}$ demonstrated that surface layer of caries lesions can be eroded almost completely by $15 \%$ hydrochloric compared to $35 \%$ phosphoric acid, thus allowing for a better resin penetration into the bulk of the carious lesion. Therefore, not only the resin itself but also the kind of etching might influence the shear bond strength.

Heliobond was chosen as a representative of an unfilled enamel bonding agent as it is an established adhesive in enamel adhesion tests ${ }^{26-28}$ and exhibit potential to penetrate early enamel lesions..$^{20,29}$ However, it has to be considered that natural enamel lesions might be much deeper than the artificial lesions created in the present study $(\sim 100 \mu \mathrm{m})$, which might lead to an incomplete penetration and, thus, reduced bond strength of the agents under clinical conditions. 
The cohesive failure modes observed in groups 2 and 3 indicate a deeper penetration of the caries infiltrant system (TEGDMA-based resin) compared to the conventional adhesive (containing BisGMA and TEGDMA) in demineralised enamel. Previous studies showed that high amounts of TEGDMA and ethanol in experimental resin infiltrants enhance the penetration capability by decreasing their viscosity and the contact angle to enamel, while a high BisGMA content influenced the penetration of the infiltrants negatively. ${ }^{30,31}$ On the other hand, increasing amounts of TEGDMA in BisGMA/TEGDMA composites were shown to increase polymerization shrinkage and polymerisation stress, ${ }^{32-34}$ which in turn might affect bond strength negatively. ${ }^{35,36}$ Bond strength might be also influenced by inhomogenities, which can be observed in the infiltrated zone. These inhomogenities were assumed to develop as a consequence of the polymerisation shrinkage, oxygen inhibition or incomplete evaporation of the solvent. 37,38

While resin infiltrants led to a complete, but partially inhomogenous penetration, Heliobond was shown to induce the formation of a homogenous layer, but penetrated only the outer part of the lesion. ${ }^{39}$ The results of the present study showed that adhesion of the flowable composite can be achieved to the same extent by the complete, but inhomogenous infiltration (caries infiltrant system) and the superficial, but homogenous layer (adhesive). As bond strength was slightly increased when the infiltrant and adhesive were combined, the bonding layer might strengthen the outermost part of the infiltrated enamel, thus increasing the adhesion of the composite.

However, due to the high hydrophilicity of TEGDMA ${ }^{40,41}$ the caries infiltrant might be more susceptible to degradation than resins containing less TEGDMA. Therefore, shear bond strength of aged specimens should be analysed in further research.

In conclusion, the use of a caries infiltrant before application of a conventional bonding does not impair bonding to sound and demineralised enamel and might be beneficial as a pretreatment in demineralised enamel. 


\section{References}

1. Kielbassa AM, Muller J, Gernhardt CR. Closing the gap between oral hygiene and minimally invasive dentistry: a review on the resin infiltration technique of incipient (proximal) enamel lesions. Quintessence International 2009;40:663-81.

2. Paris S, Meyer-Lueckel H, Colfen H, Kielbassa AM. Penetration coefficients of commercially available and experimental composites intended to infiltrate enamel carious lesions. Dental Materials 2007;23:742-8.

3. Meyer-Lueckel H, Paris S. Improved resin infiltration of natural caries lesions. Journal of Dental Research 2008;87:1112-6.

4. Paris S, Meyer-Lueckel H, Colfen H, Kielbassa AM. Penetration coefficients of commercially available and experimental composites intended to infiltrate enamel carious lesions. Dental Materials 2007;23:742-8.

5. Meyer-Lueckel H, Paris S. Progression of artificial enamel caries lesions after infiltration with experimental light curing resins. Caries Research 2008;42:117-24.

6. Phark JH, Duarte S Jr, Meyer-Lueckel H, Paris S. Caries infiltration with resins: a novel treatment option for interproximal caries. Compendium of Continuing Education in Dentistry 2009;30 Spec No 3:13-7.

7. Meyer-Lueckel H, Fejerskov O, Paris S. Novel treatment possibilities for proximal caries. Schweizer Monatsschrift für Zahnmedizin 2009;119:454-61.

8. Paris S, Meyer-Lueckel H. Inhibition of caries progression by resin infiltration in situ. Caries Research 2010;44:47-54.

9. Paris S, Meyer-Lueckel H. Masking of labial enamel white spot lesions by resin infiltration--a clinical report. Quintessence International 2009;40:713-8.

10. Fejerskov O, Nyvad B, Kidd EAM. Clinical appearance of caries lesions. In: Fejerskov O, Kidd E, eds. Dental Caries. The disease and its clinical management. Oxford: Blackwell Munksgaard, 2008:7-18. 
11. Kidd EAM, van Amerongen JP, van Amerongen WE. The role of operative treatment in caries control. In: Fejerskov O, Kidd E, eds. Dental Caries. The disease and its clinical management. Oxford: Blackwell Munksgaard, 2008:355-65.

12. de Araujo FB, de Araujo DR, dos Santos CK, de Souza MA. Diagnosis of approximal caries in primary teeth: radiographic versus clinical examination using tooth separation. American Journal of Dentistry 1996;9:54-6.

13. de Araujo FB, Rosito DB, Toigo E, dos Santos CK. Diagnosis of approximal caries: radiographic versus clinical examination using tooth separation. American Journal of Dentistry 1992;5:245-8.

14. Buskes JA, Christoffersen J, Arends J. Lesion formation and lesion remineralization in enamel under constant composition conditions. A new technique with applications. Caries Research 1985;19:490-6.

15. Schmidlin PR, Stawarczyk B, Wieland M, Attin T, Hämmerle $\mathrm{CH}$, Fischer J. Effect of different surface pre-treatments and luting materials on shear bond strength to PEEK. Dental Materials 2010;26:553-559

16. Mueller J, Meyer-Lueckel H, Paris S, Hopfenmuller W, Kielbassa AM. Inhibition of lesion progression by the penetration of resins in vitro: influence of the application procedure. Operative Dentistry 2006;31:338-45.

17. Fowler CS, Swartz ML, Moore BK, Rhodes BF. Influence of selected variables on adhesion testing. Dental Materials 1992;8:265-9.

18. Lopes MB, Sinhoreti MA, Correr SL, Consani S. Comparative study of the dental substrate used in shear bond strength tests. Pesquisa Odontologica Brasileira 2003;17:171-5.

19. Reis AF, Giannini M, Kavaguchi A, Soares CJ, Line SR. Comparison of microtensile bond strength to enamel and dentin of human, bovine, and porcine teeth. Journal of Adhesive Dentistry 2004;6:117-21. 
20. Meyer-Lueckel H, Mueller J, Paris S, Hummel M, Kielbassa AM. The penetration of various adhesives into early enamel lesions in vitro. Schweizer Monatsschrift für Zahnmedizin 2005;115:316-23.

21. Meyer-Lueckel H, Paris S, Mueller J, Colfen H, Kielbassa AM. Influence of the application time on the penetration of different dental adhesives and a fissure sealant into artificial subsurface lesions in bovine enamel. Dental Materials 2006;22:22-8.

22. Paris S, Meyer-Lueckel H, Mueller J, Hummel M, Kielbassa AM. Progression of sealed initial bovine enamel lesions under demineralizing conditions in vitro. Caries Research 2006;40:124-9.

23. Mueller J, Meyer-Lueckel H, Paris S, Hopfenmuller W, Kielbassa AM. Inhibition of lesion progression by the penetration of resins in vitro: influence of the application procedure. Operative Dentistry 2006;31:338-45.

24. Paris S, Meyer-Lueckel H, Kielbassa AM. Resin infiltration of natural caries lesions. Journal of Dental Research 2007;86:662-6.

25. Paris S, Dorfer CE, Meyer-Lueckel H. Surface conditioning of natural enamel caries lesions in deciduous teeth in preparation for resin infiltration. Journal of Dentistry 2010;38:65-71.

26. Schmidlin PR, Schatzle M, Fischer J, Attin T. Bonding of brackets using a cariesprotective adhesive patch. Journal of Dentistry 2008;36:125-9.

27. Cura C, Saracoglu A, Cotert HS. Effect of different bonding agents on shear bond strengths of composite-bonded porcelain to enamel. Journal of Prosthetic Dentistry 2003;89:394-9.

28. Foek DL, Ozcan M, Krebs E, Sandham A. Adhesive properties of bonded orthodontic retainers to enamel: stainless steel wire vs fiber-reinforced composites. Journal of Adhesive Dentistry 2009;11:381-90.

29. Meyer-Lueckel H, Paris S, Mueller J, Colfen H, Kielbassa AM. Influence of the application time on the penetration of different dental adhesives and a fissure sealant into artificial subsurface lesions in bovine enamel. Dental Materials 2006;22:22-8. 
30. Paris S, Meyer-Lueckel H, Colfen H, Kielbassa AM. Resin infiltration of artificial enamel caries lesions with experimental light curing resins. Dental Materials Journal 2007;26:582-8.

31. Paris S, Meyer-Lueckel H, Colfen H, Kielbassa AM. Penetration coefficients of commercially available and experimental composites intended to infiltrate enamel carious lesions. Dental Materials 2007;23:742-8.

32. Goncalves F, Pfeifer CC, Stansbury JW, Newman SM, Braga RR. Influence of matrix composition on polymerization stress development of experimental composites. Dental Materials 2010;26:697-703

33. Goncalves F, Pfeifer CS, Ferracane JL, Braga RR. Contraction stress determinants in dimethacrylate composites. Journal of Dental Research 2008;87:367-71.

34. Sun J, Lin-Gibson S. X-ray microcomputed tomography for measuring polymerization shrinkage of polymeric dental composites. Dental Materials 2008;24:228-34.

35. Ilie N, Kunzelmann KH, Hickel R. Evaluation of micro-tensile bond strengths of composite materials in comparison to their polymerization shrinkage. Dental Materials 2006;22:593-601.

36. Asmussen E, Peutzfeldt A. Short- and long-term bonding efficacy of a self-etching, onestep adhesive. Journal of Adhesive Dentistry 2003;5:41-5.

37. Paris S, Meyer-Lueckel H, Colfen $\mathrm{H}$, Kielbassa AM. Resin infiltration of artificial enamel caries lesions with experimental light curing resins. Dental Materials Journal $2007 ; 26: 582-8$

38. Meyer-Lueckel H, Paris S, Mueller J, Colfen H, Kielbassa AM. Influence of the application time on the penetration of different dental adhesives and a fissure sealant into artificial subsurface lesions in bovine enamel. Dental Materials 2006;22:22-8.

39. Meyer-Lueckel H, Paris S, Mueller J, Colfen H, Kielbassa AM. Influence of the application time on the penetration of different dental adhesives and a fissure sealant into artificial subsurface lesions in bovine enamel. Dental Materials 2006;22:22-8. 
40. Ortengren $U$, Wellendorf $H$, Karlsson S, Ruyter IE. Water sorption and solubility of dental composites and identification of monomers released in an aqueous environment. Journal of Oral Rehabilitation 2001;28:1106-15.

41. Sideridou ID, Karabela MM, Vouvoudi EC. Volumetric dimensional changes of dental light-cured dimethacrylate resins after sorption of water or ethanol. Dental Materials 2008;24:1131-6. 


\begin{tabular}{|c|c|c|c|}
\hline Product & Composition & Lot number & Manufacturer \\
\hline Heliobond & Bis-GMA, TEGDMA, initiators, stabilizers & L24292 & $\begin{array}{l}\text { Ivoclar Vivadent, } \\
\text { Schaan, Liechtenstein }\end{array}$ \\
\hline \multirow{3}{*}{ Icon } & $\begin{array}{l}\text { Icon etch: } \\
15 \% \text { hydrochloric acid, water, pyrogenic } \\
\text { silica, tenside, pigments }\end{array}$ & \multirow{3}{*}{632178} & \multirow{3}{*}{$\begin{array}{l}\text { DMG, Hamburg, } \\
\text { Germany }\end{array}$} \\
\hline & $\begin{array}{l}\text { Icon Dry: } \\
\text { ethanol }\end{array}$ & & \\
\hline & $\begin{array}{l}\text { Icon Infiltrant: } \\
\text { triethylenglycoldimethacrylate-based resin }\end{array}$ & & \\
\hline
\end{tabular}

\section{Table 1.}

Composition of the conventional adhesive and the caries infiltrant system accordingly to the manufacturers information 


\begin{tabular}{|c|c|c|c|c|}
\hline \multirow[t]{2}{*}{ Enamel } & \multirow[t]{2}{*}{ Groups } & \multirow{2}{*}{$\begin{array}{c}\text { Mean shear bond } \\
\text { strength }(\mathrm{MPa}) \pm \mathrm{SD} \\
(95 \% \mathrm{Cl})\end{array}$} & \multicolumn{2}{|c|}{$\begin{array}{l}\text { Relative frequency }(\%) \text { of } \\
\text { failure type }(95 \% \mathrm{Cl})\end{array}$} \\
\hline & & & adhesive & cohesive \\
\hline \multirow{3}{*}{ sound } & Adhesive & $\begin{array}{l}14.8 \pm 4.8^{\mathrm{a}} \\
(12.8 ; 16.8)\end{array}$ & $\begin{array}{c}100 \\
(83.1 ; 100)\end{array}$ & $\begin{array}{c}0 \\
(0 ; 16.8)\end{array}$ \\
\hline & Infiltrant & $\begin{array}{l}12.9 \pm 3.8^{\mathrm{a}} \\
(11.0 ; 14.7)\end{array}$ & $\begin{array}{c}100 \\
(83.1 ; 100)\end{array}$ & $\begin{array}{c}0 \\
(0 ; 16.8)\end{array}$ \\
\hline & Infiltrant + Adhesive & $\begin{array}{l}13.9 \pm 3.4^{\mathrm{a}} \\
(12.3 ; 15.6)\end{array}$ & $\begin{array}{c}100 \\
(83.1 ; 100)\end{array}$ & $\begin{array}{c}0 \\
(0 ; 16.8)\end{array}$ \\
\hline \multirow{3}{*}{ demineralised } & Adhesive & $\begin{array}{l}15.0 \pm 5.1^{\mathrm{a}} \\
(12.6 ; 17.5)\end{array}$ & $\begin{array}{c}85 \\
(62.1 ; 96.8)\end{array}$ & $\begin{array}{c}15 \\
(3.2 ; 37.9)\end{array}$ \\
\hline & Infiltrant & $\begin{array}{l}17.5 \pm 4.0^{a, b} \\
(15.6 ; 19.4)\end{array}$ & $\begin{array}{c}60 \\
(36.0 ; 80.9)\end{array}$ & $\begin{array}{c}40 \\
(19.1 ; 64.0)\end{array}$ \\
\hline & Infiltrant + Adhesive & $\begin{array}{l}19.8 \pm 4.9^{b} \\
(17.5 ; 22.1)\end{array}$ & $\begin{array}{c}35 \\
(15.3 ; 59.2)\end{array}$ & $\begin{array}{c}65 \\
(40.7 ; 84.6)\end{array}$ \\
\hline
\end{tabular}

\section{Table 2}

Shear bond strength values ( $\mathrm{MPa}$, mean \pm standard deviation, 95\% Cl) and relative frequency of failures types $(\%, 95 \% \mathrm{Cl})$ in sound and demineralised specimens (each group $\mathrm{n}=20$ ) after treatment with the conventional adhesive, the caries infiltrant system or a combination of both. Within sound and demineralised specimens, respectively, shear bond strength values which are not significantly different are marked with the same letter. Cohesive failures occurred only in enamel. 